\title{
Characteristics of patients with COPD newly prescribed a long-acting bronchodilator: a retrospective cohort study
}

This article was published in the following Dove Press journal: International Journal of COPD

25 September 2014

Number of times this article has been viewed

\author{
Keele E Wurst ${ }^{\prime}$ \\ Samantha St Laurent' \\ Hana Mullerova ${ }^{2}$ \\ Kourtney J Davis ${ }^{3}$ \\ 'Worldwide Epidemiology, \\ GlaxoSmithKline R\&D, Research \\ Triangle Park, NC, USA; ${ }^{2}$ Worldwide \\ Epidemiology, GlaxoSmithKline \\ R\&D, Uxbridge, UK; ${ }^{3}$ Worldwide \\ Epidemiology, GlaxoSmithKline \\ R\&D, Wavre, Belgium
}

Introduction: This study aimed to characterize patients with chronic obstructive pulmonary disease (COPD) newly prescribed a long-acting bronchodilator (LABD), and to assess changes in medication over 24 months.

Methods: A cohort of patients with COPD aged $\geq 40$ years newly prescribed an LABD between January 1, 2007 and December 31, 2009 were identified from the Truven Marketscan ${ }^{\circledR}$ Commercial Database (Truven Health Analytics, Ann Arbor, MI, USA) and followed for 24 months. Inclusion criteria included no prior prescription for an LABD or inhaled corticosteroids for 12 months prior to the LABD index date (baseline). Patient characteristics were examined. As LABDs were mainly long-acting muscarinic antagonists (LAMAs), additions, switches, discontinuation, adherence to (medication possession ratio), and persistence (proportion of days covered) with LAMA monotherapy were assessed for 24 months following the index date. Adherence and persistence with long-acting $\beta_{2}$-agonists (LABAs) were also assessed.

Results: A cohort of 3,268 patients aged 40-65 years was identified (mean age 55.8 years, $48 \%$ male). LAMA monotherapy was prescribed to $93 \%$ of patients who received an LABD. During the 24 -month follow-up, $16 \%$ of these patients added COPD medication, $10 \%$ switched to an inhaled corticosteroid-containing medication, and $25 \%$ discontinued after one LAMA prescription at baseline. Over 12 and 24 months, adherence to LAMA was 40\% and 33\%, respectively, and adherence to LABA was $29 \%$ and $24 \%$, respectively. Over the same time periods, persistence with LAMA monotherapy was $19 \%$ and $15 \%$, respectively, and persistence with LABA was $9 \%$ and $7 \%$, respectively.

Conclusion: Adherence to newly initiated LAMA monotherapy was low, with one in four patients adding to or switching from LAMA and many patients discontinuing therapy. Adherence to LABA was also low. These results suggest that additional medication to a single LABD may be required in some patients with COPD to achieve optimal disease control.

Keywords: adherence, COPD, long-acting bronchodilator, persistence, switching

\section{Introduction}

Chronic obstructive pulmonary disease (COPD) is characterized by progressive and irreversible airflow obstruction, ${ }^{1}$ which is associated with an abnormal inflammatory response. ${ }^{2}$ The characteristic symptoms of COPD are chronic and progressive dyspnea, cough, and sputum production. ${ }^{3}$ Dyspnea is one of the most common symptoms of COPD, and its management is crucial for achieving optimal disease control. ${ }^{4}$ Drugs such as long-acting bronchodilators (LABDs) that alter bronchial smooth muscle tone and increase inspiratory capacity have the potential to provide relief for the dyspneic patient. ${ }^{4}$ However, many patients with COPD who receive LABD monotherapy may continue to experience significant symptoms, and thus may need to add or switch to
Correspondence: Keele E Wurst

Worldwide Epidemiology,

GlaxoSmithKline R\&D, 5 Moore Drive,

Research Triangle Park, NC 27709, USA

Tel + I 9194837994

$\mathrm{Fax}+19193158747$

Email keele.e.wurst@gsk.com 
other medications to manage symptoms and improve functional status and outcomes. ${ }^{5}$

A range of medications are used in the management of COPD, including short-acting bronchodilators (SABDs), LABDs, and inhaled corticosteroids (ICSs). SABDs include short-acting $\beta_{2}$-agonists and short-acting muscarinic antagonists. LABDs include long-acting $\beta_{2}$-agonists (LABAs), long-acting muscarinic antagonists (LAMAs), and LABAs and LAMAs in combination. LABAs may also be prescribed in combination with ICS. At the time of this study, three LABDs were approved in the US for the treatment of COPD: formoterol (an LABA), salmeterol (an LABA), and tiotropium (an LAMA).

The 2006, 2011, and 2013 Global Initiative for Chronic Obstructive Lung Disease (GOLD) strategies group patients with COPD by airflow limitation, symptoms, and risk of exacerbations. ${ }^{3,6,7}$ After SABD monotherapy, the recommended first-line maintenance medication in patients with COPD is LABA or LAMA monotherapy. Long-term ICSs with an LABD or a combination of LABDs is recommended in patients with high risk of exacerbations. ${ }^{7}$

Previous observational studies have assessed the use of respiratory medications in patients with COPD in Canada ${ }^{8}$ and Europe. ${ }^{9-11}$ Persistence with inhaled medication was generally poor. In patients initiating an $\mathrm{LABD}, 12$-month persistence rates were $25 \%-64 \%$ for LAMA monotherapy ${ }^{8-11}$ and 13\%-27\% for LABA monotherapy. ${ }^{9,11}$ Treatment evolution (ie, changes in medication patterns) in patients who are newly treated with LABD medication within the US has not been evaluated. The main objectives of this study were to: 1) describe baseline characteristics in those patients with COPD newly prescribed an LABD; 2) determine treatment evolution (treatment additions, switches, and discontinuations, and those adherent and/or persistent) over 12 and 24 months in patients with COPD prescribed an LABD; and 3) describe patient and disease burden characteristics with regard to treatment evolution.

\section{Methods \\ Study design}

In this retrospective cohort study, patients were identified from the Truven Marketscan ${ }^{\circledR}$ Commercial Database (Truven Health Analytics, Ann Arbor, MI, USA). This database contains more than 500,000,000 claim records from more than 170,000,000 individual patients since 1995, including inpatient, outpatient, and pharmacy dispensing claims for individuals employed in the US from employer-based health plans. ${ }^{12}$ The Truven Marketscan ${ }^{\circledR}$ Commercial Database is fully compliant with the Health Insurance Portability and Accountability Act. Anonymized patient data were analyzed. All codes used to identify medical conditions or different medications were reviewed by a clinician or pharmacist.

\section{Patients}

A cohort of patients with COPD newly prescribed an LABD between January 1, 2007 and December 31, 2009 was identified. Patients were required to be aged 40 years and above (data coverage ends at 65 years), have at least 12 months' history prior to the LABD index date (baseline), at least 24 months of follow-up, and at least one COPDrelated diagnostic code (International Classification of Diseases [ICD]-9 codes: 491, 491.x, 491.xx, 492, 492.x, and 496) within their prior 12-month history. Patients were excluded if they had a record for dispensed LABD or ICS within their prior 12-month history, a record for ICS use at the LABD index date, or a code for any other significant respiratory disorder that can interfere with clinical COPD diagnosis or substantially change the natural history of the COPD at any time in their available patient history (including tuberculosis, cystic fibrosis, bronchiectasis, idiopathic pulmonary fibrosis, congenital anomalies of the larynx, trachea, and bronchus, idiopathic interstitial pneumonia, and acute bronchospasm).

\section{Study variables}

Patient characteristics were assessed at baseline, and included age, sex, and comorbid conditions at any time in their prior history or at baseline. Comorbid conditions were assessed using the Charlson's comorbidity index, adjusted by removing COPD and acquired immunodeficiency syndrome (due to very low prevalence of reporting in the general population) and adding conditions of depression and asthma. ${ }^{13}$

Markers of disease severity were assessed at baseline (including prior 12-month history), and at 12 months (0-12 months) and 24 months (0-24 months) of follow-up. Markers included COPD exacerbation history, oral corticosteroid (OCS) use, all-cause hospitalizations, emphysema diagnosis (ICD-9 codes: 492, 492.0, and 492.8), use of oxygen therapy (medical code for oxygen therapy or procedural code for oxygen), ICD-9 codes for prior lower respiratory tract infections (list available on request), SABD prescriptions, and shortness of breath (ICD-9 code: 786.05). Exacerbations of COPD were classified as severe or moderate episodes. A severe episode was defined as a COPD-related emergency department visit (identified by a medical dataset record with an emergency department as the place of service or a Current 
Procedural Terminology code between 99281-99288 without a confinement identification) or hospitalization (episode with a confinement identification) with multiple records on the same date counted as a single visit. A moderate episode (community treated) was defined as any one of the following events: COPD exacerbation diagnosis or acute bronchitis diagnosis (ICD-9 codes: 491.21, 491.22, 494.1, 466, 466.x, and 466.xx); asthma exacerbation diagnosis (ICD-9 codes: 493.12, 493.22, and 493.92) with prior history of two or more COPD codes; bronchitis, not specified as acute or chronic (ICD-9 codes: 490, 490.x, and 490.xx in addition to obstructive chronic bronchitis [491.2]) with antibiotics and OCS within 5 days of each other; or antibiotic and OCS dispensing on the same day. If more than one of these events occurred within 14 days from each other, the first event was taken as the start of the episode.

Respiratory medications were defined as a prescription dispensed by a pharmacy according to the linked pharmacy claim. Changes in respiratory medication from index LABD use at baseline were evaluated at 12 and 24 months of follow-up. Medications were considered combinations if they were prescribed together on the same day or had an overlapping day supply (or occurred within 30 days if day supply was missing). Concurrent dispensing for as-needed SABDs was not considered as a combination medication and was evaluated separately.

\section{Data analysis}

This study was entirely descriptive. Treatment evolution was analyzed in patients who initiated LABD monotherapy. As the majority of LABDs were LAMAs, in this group only, additions, switches, and discontinuations were assessed for 24 months following the index date. Adherence to (medication possession ratio, MPR; see below for definition) and persistence with (proportion of days covered, PDC; see below for definition) medication were calculated for both LAMA and LABA monotherapy.

Additions to, switches from, and discontinuation of LAMA monotherapy were assessed over the 12 and 24 months of follow-up. Prescriptions were defined as a prescription dispensed by a pharmacy according to the linked pharmacy claim. An addition was defined as a prescription code for an additional respiratory medication overlapping with the prescription of the LAMA. Patients were required to remain on both the LAMA and the additional pharmacotherapy for at least 60 days (two refills).

Treatment switching from LAMA monotherapy to other inhaled COPD medications was defined as a prescription for an alternative inhaled COPD medication within 90 days following exhaustion of the LAMA prescription and no continued use of the LAMA. Patients could have more than one treatment switch during follow-up. Discontinuation was defined as no subsequent LAMA prescription or one additional prescription for LAMA in the 24 months of follow-up.

Adherence to and persistence with LABD monotherapy were assessed at 12 and 24 months of follow-up. Adherence to LABD monotherapy was defined as an MPR of at least $80 \%$. The MPR was calculated by the sum of the days supplied for all but the last repeat prescription divided by the number of days between the first and last repeat prescription. ${ }^{14}$ Patients were required to have at least two prescriptions for the LABD to be included in this calculation. Adherence to LABD was calculated among all patients prescribed LABD at baseline, regardless of whether patients added to LABD monotherapy during the follow-up. Persistence with LABD monotherapy was defined as a PDC of at least $80 \%$. The PDC was calculated using the number of days that the LABD was prescribed divided by the total number of days in the specified time interval. The cut-offs used to define adherence and persistence are supported by the International Society for Pharmacoeconomic and Outcomes Research. ${ }^{15}$

Patient characteristics and markers of disease severity were compared in patients who added to, switched from, or discontinued LAMA monotherapy. Possible reasons for adding to or switching from LAMA monotherapy to an ICS-containing medication were also assessed.

\section{Results \\ Patients}

From the Truven commercial population of 58,975,728 between 2007 and 2009, 170,304 patients with an LABD prescription were identified. Of these, 153,131 were aged over 40 years at the index date. The number of patients with conditions incompatible with COPD was 134,804. Of the remaining patients, 16,992 had 12 months of data before the LABD index date and 24 months of follow-up data. The number of patients with no previous LABD prescription in the previous 12 months was 11,341. A diagnosis of COPD within 12 months of the LABD index date was identified in 6,594 patients. Data from 3,268 patients with no exposure to ICS in their prior 12-month history or at baseline were included in this study.

\section{Patient characteristics}

Patients had a mean age of 55.8 years and $48 \%$ were men. Most patients (93\%) were prescribed LAMA monotherapy at 
baseline, with fewer patients prescribed LABA monotherapy $(6 \%)$ or LABA and LAMA concurrently $(2 \%)$. Patients prescribed LAMA had a lower prevalence of asthma, cerebrovascular disease, congestive heart disease, depression, and mild liver disease than patients receiving other LABDs (Table 1).

\section{Medication evolution from index LABD prescription}

The percentage of patients who received the same LABD medication as their index decreased over time. At 3 and 24 months of follow-up, respectively, the proportion of patients receiving the same LABD as their index was $44 \%$ and $14 \%$ for LABA monotherapy, $54.7 \%$ and $26.1 \%$ for LAMA monotherapy, and $50.9 \%$ and $18.9 \%$ for LABA plus LAMA (Figure 1).

\section{Additions}

Of the 3,022 patients who initiated LAMA monotherapy, a total of 312 patients $(10 \%)$ added medication within 12 months of follow-up, and a total of 497 patients $(16 \%)$ added medication within 24 months of follow-up. Compared with patients who had only LAMA prescriptions, patients who added medication had increased prevalence of comorbidities, higher frequency of exacerbations (particularly at least two exacerbations), and had more SABD prescriptions dispensed during 24 months of follow-up (Table 2). Within 24 months of follow-up, 418 patients (84\% of patients who added therapy) progressed to triple therapy, with the addition of LABA plus ICS. The mean (standard deviation [SD]) time to progression to triple therapy was 306.7 (209.3) days. Among patients who initiated LAMA monotherapy, the number of patients who added therapy during 24 months of follow-up was greater among those who had an asthma diagnosis (prior or current) than in those without an asthma diagnosis: $230(21 \%)$ versus $267(13 \%)$.

\section{Switches}

Within 12 months of follow-up, 266 (9\%) patients switched medication, of whom 49 (18\%) switched to ICS monotherapy and $213(80 \%)$ switched to ICS plus LABA. The mean (SD) time to first switch within 12 months of follow-up was 182.7 (96.5) days. Within 24 months of follow-up, 327 patients (11\%) switched medication, of whom 71 (22\%) switched to ICS monotherapy and 261 (80\%) switched to ICS plus LABA (Figure 2). The mean (SD) time to first switch within 24 months of follow-up was 286.4 (198.3) days. Compared with patients who had only LAMA prescriptions, patients who switched to an ICScontaining medication had increased prevalence of comorbidities, higher frequency of exacerbations (particularly at least two moderate exacerbations), and more prescriptions

Table I Baseline characteristics of patients prescribed LABD medication ${ }^{\mathrm{a}}$

\begin{tabular}{|c|c|c|c|c|}
\hline \multirow[t]{2}{*}{ Characteristic } & \multicolumn{4}{|c|}{ Medication received } \\
\hline & Any LABD & LABA & LAMA & LABA + LAMA \\
\hline All patients & $3,268(100.0)$ & $193(5.9)$ & $3,022(92.5)$ & $53(1.6)$ \\
\hline Male & $\mathrm{I}, 557(47.6)$ & $87(45.1)$ & $\mathrm{I}, 444(47.8)$ & $26(49.1)$ \\
\hline Age, mean (SD) & $55.8(5.4)$ & $56.2(5.4)$ & $55.6(5.4)$ & $55.8(4.8)$ \\
\hline \multicolumn{5}{|l|}{ Region $^{\mathrm{b}}$} \\
\hline Northeast & $344(10.5)$ & I7 (8.8) & $323(10.7)$ & $4(7.5)$ \\
\hline North Central & $836(25.6)$ & $39(20.2)$ & $790(26.1)$ & $7(\mid 3.2)$ \\
\hline South & I,733 (53.0) & $104(53.9)$ & I,59I (52.6) & $38(71.7)$ \\
\hline West & $333(10.2)$ & $31(16.1)$ & $299(9.9)$ & $3(5.7)$ \\
\hline Unknown & $22(0.7)$ & $2(1.0)$ & $19(0.6)$ & $\mathrm{I}(1.9)$ \\
\hline \multicolumn{5}{|l|}{ Comorbidities } \\
\hline Charlson comorbidity index, mean (SD) & $1.6(2.2)$ & $1.8(2.2)$ & $1.6(2.2)$ & I.8 (2.0) \\
\hline Asthma & $1,205(36.9)$ & $102(52.8)$ & $1,076(35.6)$ & $27(50.9)$ \\
\hline Cancer & $453(13.9)$ & $18(9.3)$ & $429(14.2)$ & $6(11.3)$ \\
\hline Cerebrovascular disease & $696(21.3)$ & $55(28.5)$ & $623(20.6)$ & $18(34.0)$ \\
\hline Congestive heart disease & $552(16.9)$ & $46(23.8)$ & $494(16.3)$ & $12(22.6)$ \\
\hline Depression & $885(27.1)$ & $59(30.6)$ & $809(26.8)$ & $17(32.1)$ \\
\hline Mild liver disease & $484(14.8)$ & 37 (19.2) & $438(14.5)$ & $9(17.0)$ \\
\hline Moderate liver disease & $31(0.9)$ & $\mathrm{I}(0.5)$ & $29(1.0)$ & $\mathrm{I}(1.9)^{\prime}$ \\
\hline Myocardial infarction & $305(9.3)$ & $22(11.4)$ & $280(9.3)$ & $3(5.7)$ \\
\hline
\end{tabular}

Notes: All values are $\mathrm{n}(\%)$ unless stated otherwise; a patients had not received inhaled corticosteroids at the LABD index date or during the I2-month prior history; ${ }^{\mathrm{b}}$ the regional distribution of patients in this study was similar to the overall regional distribution within the database.

Abbreviations: LABA, long-acting $\beta_{2}$-agonist; LABD, long-acting bronchodilator; LAMA, long-acting muscarinic antagonist; SD, standard deviation. 


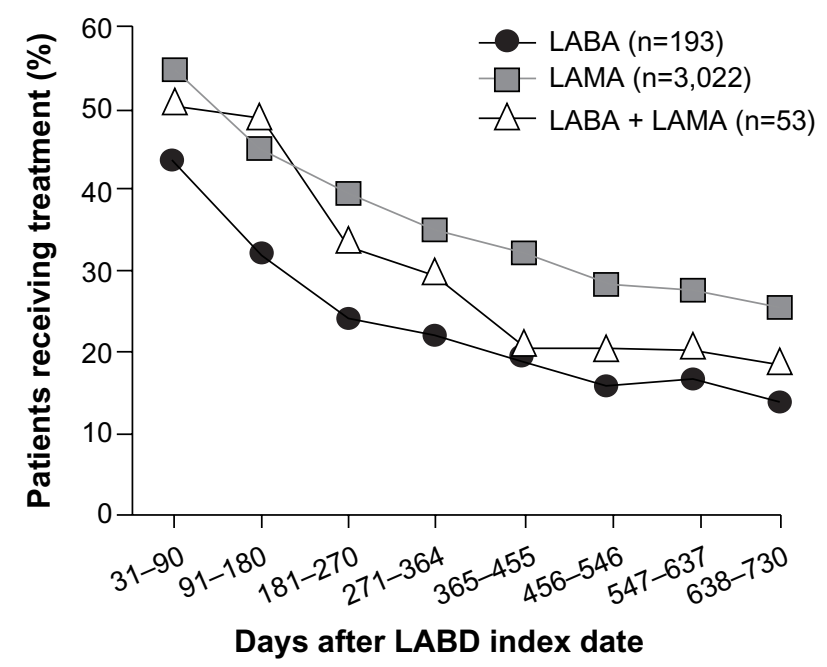

Figure I Percentage of new users of LABD receiving the same treatment at the index date at specified time intervals $(n=3,268)$.

Notes: Patients had not received inhaled corticosteroids at the LABD index date or during the 12-month prior history. The percentage receiving treatment at the index date was $100 \%$ for all patients because they were all new users of LABD.

Abbreviations: LABA, long-acting $\beta_{2}$-agonist; $L A B D$, long-acting bronchodilator; LAMA, long-acting muscarinic antagonist.

for SABD during the 24 months of follow-up. Compared with patients who added to LAMA monotherapy, patients who switched to an ICS-containing medication had a higher prevalence of asthma and myocardial infarction (Table 2). Among patients who initiated LAMA monotherapy, the percentage of patients who switched to an ICS-containing therapy during 24 months of follow-up was greater among those who had an asthma diagnosis than in those without an asthma diagnosis: $183(17 \%)$ versus $130(7 \%)$.

\section{Discontinuations}

Of the patients who initiated LAMA monotherapy, 744 (25\%) had only one LAMA prescription at baseline and $382(13 \%)$ had only one prescription at baseline followed by one additional prescription within 24 months of follow-up (Table 2). One and two LAMA prescriptions during 24 months were observed in 256 (24\%) and 126 (12\%) patients with an asthma diagnosis, respectively, and in $488(25 \%)$ and $256(13 \%)$ patients without an asthma diagnosis, respectively.

\section{Events in 30 days prior to addition or switch}

In the 30 days before an addition or switch, approximately $20 \%$ of patients had an event (exacerbations, lower respiratory tract infections, or shortness of breath) recorded. Among the patients who had an event in the 30 days before a switch or addition, the most frequent event in the 30 days prior to an addition or switch of medication in patients prescribed LAMA monotherapy at baseline was a diagnosis of lower respiratory tract infection; the next most frequent events prior to an addition or switch were moderate exacerbations and shortness of breath. Of the patients with shortness of breath diagnosed in the 30 days prior to an addition or switch of medication, approximately half had shortness of breath only and the other half had shortness of breath concurrent with either lower respiratory tract infection or exacerbations. The majority of patients with an exacerbation in the 30 days prior to an addition or switch also had claims with diagnoses of shortness of breath or a lower respiratory tract infection recorded (Table 3).

\section{Adherence}

Adherence to LAMA monotherapy from baseline was $40 \%$ after 12 months of follow-up (mean [SD] MPR: 65.3\% [28.82\%]) and 33\% after 24 months of follow-up (mean [SD] MPR: 59.2\% [30.75\%]). Compared with patients who were nonadherent, patients who were adherent were more likely to be men, had more frequent prescription dispensings for $\mathrm{SABD}$, and had more emphysema diagnoses during 24 months of follow-up. Patients who were nonadherent had higher frequency of comorbidities (particularly asthma, depression, and mild liver disease) and more frequent exacerbations and all-cause hospitalizations during 24 months of follow-up (Table 4). At 24 months, there were 221 (21\%) patients with an asthma diagnosis who were adherent compared with $506(26 \%)$ without an asthma diagnosis who were adherent. At 12 and 24 months, 30 (29.4\%) and 27 (24\%) of patients were adherent to LABA (mean [SD] MPR: 59.5\% [28.82\%] and 52.7\% [29.39\%]).

\section{Persistence with medication}

During the first 12 months of follow-up, 19\% of patients were persistent with LAMA medication (had prescriptions for at least $80 \%$ of the year). In the first 12 months of follow-up, patients who initiated LAMA monotherapy, on average, only had prescriptions for $40 \%$ of the year (mean [SD] PDC: 39.7\% [32.16\%]). During 24 months of follow-up, just $15 \%$ of patients had prescriptions to cover at least $80 \%$ of the time, and the PDC decreased to $33 \%$ (mean [SD] PDC: $32.94 \%$ [32.06\%]). Compared with patients who were not persistent with LAMA monotherapy, patients who were persistent had a higher frequency of prescription dispensings for SABD and had more emphysema diagnoses during the 24-month follow-up. Patients who were not persistent with LAMA monotherapy had increased prevalence 


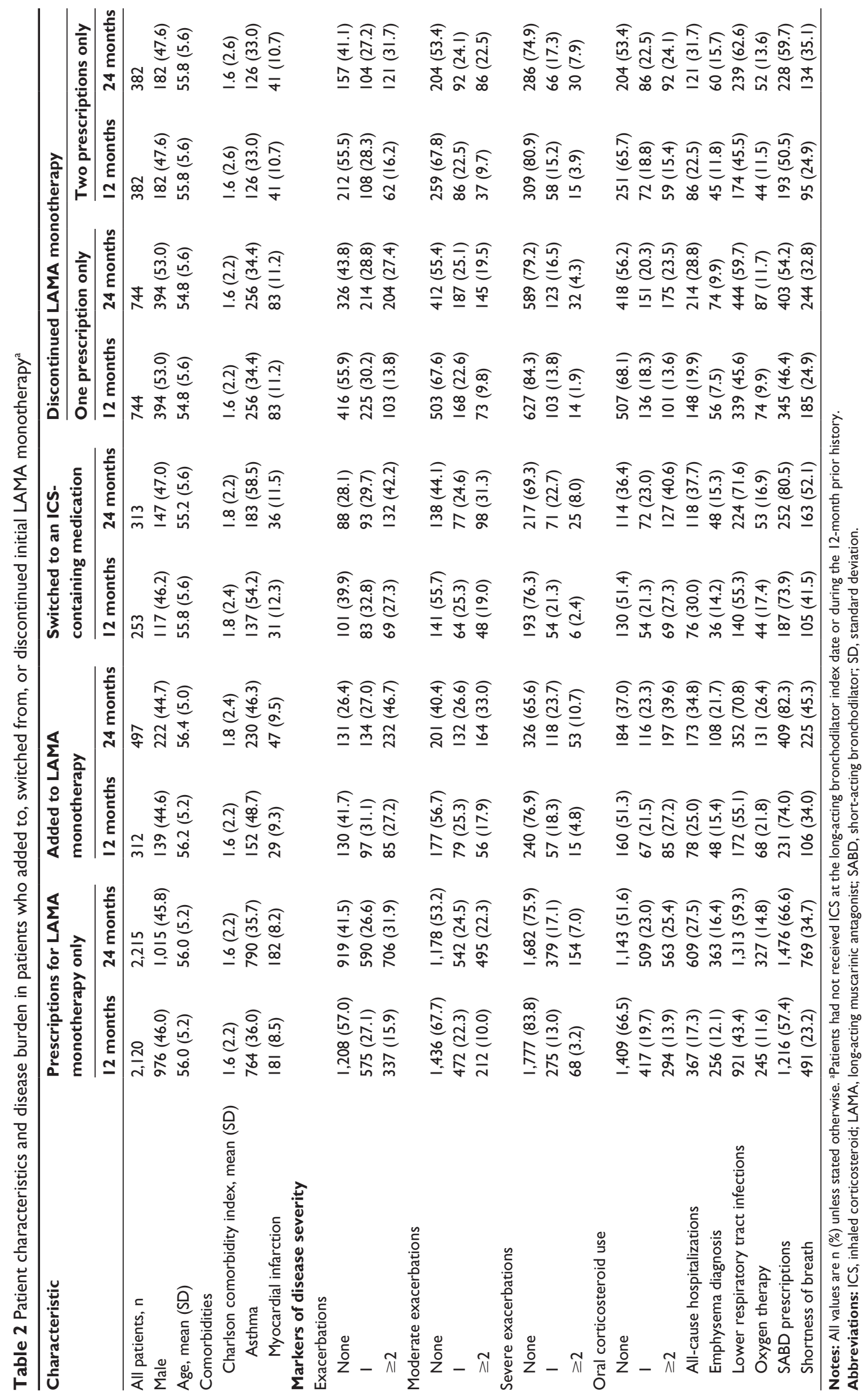




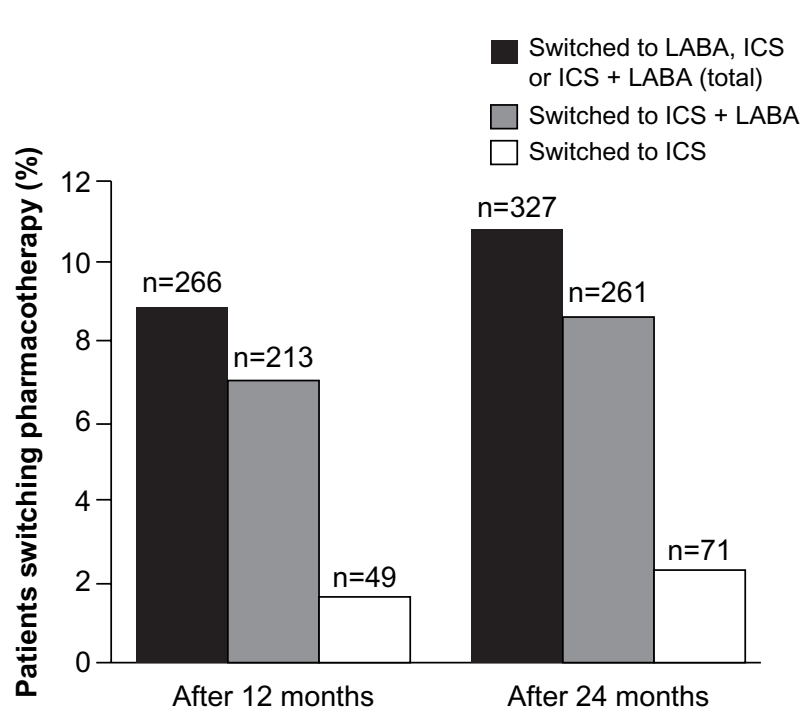

Figure 2 Medication switches in patients initially prescribed long-acting muscarinic antagonist monotherapy $(n=3,022)$.

Notes: Patients had not received ICS at the long-acting bronchodilator index date or during the 12-month prior history. Switching categories was not mutually exclusive - patients could have been counted in the ICS and ICS + LABA groups if more than one switch occurred.

Abbreviations: ICS, inhaled corticosteroids; LABA, long-acting $\beta_{2}$-agonist.

of comorbidities (particularly asthma, depression, and mild liver disease), more exacerbations, and more all-cause hospitalizations during 24 months of follow-up (Table 4). At 24 months, 140 (13\%) patients with an asthma diagnosis were persistent compared with 309 (16\%) patients without an asthma diagnosis. During 12 and 24 months of follow-up, 17 (9\%) and 14 (7\%) patients were persistent with LABA therapy (mean [SD] PDC: $28.8 \%[27.51 \%]$ and $22.3 \%[26.22 \%])$.

\section{Discussion}

In this retrospective cohort study of patients with COPD newly prescribed LABD medication, most patients (93\%) initiated LAMA monotherapy rather than LABA or LABA plus LAMA. Approximately one in four patients who initiated LAMA monotherapy added to or switched respiratory medication over the 24-month study period. In comparison to patients receiving LABA initially, more patients receiving LAMA monotherapy initially received the same medication through 24 months of follow-up. Patients with an asthma diagnosis (previous or concurrent) had more additions and switches and lower adherence and persistence with LAMA therapy than patients without an asthma diagnosis. The patients who added or switched COPD medication had more severe COPD, as they had increased prevalence of comorbidities, more frequent exacerbations, and more SABD prescriptions than patients who did not add or switch. Because COPD is progressive, increases in the frequency or severity of exacerbations can be indicative of more severe disease. ${ }^{16}$ In addition to increased disease severity, there are many other potential reasons why patients may change or discontinue medication, and the actual reasons cannot be deduced from this database. Potential reasons include, but are not limited to, patient perception of their disease, adverse drug reactions, and cognitive defects. ${ }^{17-20}$ It is

Table 3 Events recorded in the 30 days prior to first treatment switch or addition in patients initially prescribed LAMA monotherapy ${ }^{\mathrm{a}}$

\begin{tabular}{|c|c|c|}
\hline Description, n (\%) & $\begin{array}{l}\text { Added to LAMA } \\
\text { monotherapy }(n=497)\end{array}$ & $\begin{array}{l}\text { Switched from LAMA to } \\
\text { ICS or ICS + LABA }(n=3 \mid 3)\end{array}$ \\
\hline Moderate exacerbation & $77(15.5)$ & $37(11.8)$ \\
\hline Severe exacerbation & $37(7.4)$ & $18(5.8)$ \\
\hline Any exacerbation & $97(19.5)$ & $48(15.3)$ \\
\hline $\begin{array}{l}\text { Also had lower respiratory tract infection } \\
\text { and shortness of breath }\end{array}$ & $23(4.6)$ & II (3.5) \\
\hline Also had lower respiratory tract infection & $49(9.9)$ & $22(7.0)$ \\
\hline Also had shortness of breath & $4(0.8)$ & $6(1.9)$ \\
\hline Exacerbation only & $21(4.2)$ & $9(2.9)$ \\
\hline All-cause hospitalization & $33(6.6)$ & $20(6.4)$ \\
\hline Emphysema & $22(4.4)$ & $5(1.6)$ \\
\hline Lower respiratory tract infection & $84(16.9)$ & $43(13.7)$ \\
\hline Shortness of breath & $61(12.3)$ & $33(10.5)$ \\
\hline $\begin{array}{l}\text { Also had lower respiratory tract infection } \\
\text { and exacerbation }\end{array}$ & $23(4.6)$ & II (3.5) \\
\hline Also had lower respiratory tract infection & $2(0.4)$ & 0 \\
\hline Also had exacerbation & $4(0.8)$ & $6(1.9)$ \\
\hline Shortness of breath only & $32(6.4)$ & $16(5.1)$ \\
\hline
\end{tabular}

Notes: aPatients had not received ICS at the long-acting bronchodilator index date or during the I2-month prior history. Categories are not mutually exclusive. Note that it may be difficult to distinguish between an exacerbation and a lower respiratory tract infection in a clinical setting. Abbreviations: ICS, inhaled corticosteroids; LABA, long-acting $\beta_{2}$-agonist; LAMA, long-acting muscarinic antagonist. 
Table 4 Patient characteristics and disease burden in patients who are adherent to, nonadherent to, persistent with, and not persistent with LAMA monotherapy

\begin{tabular}{|c|c|c|c|c|c|c|c|c|}
\hline \multirow[t]{2}{*}{ Characteristic } & \multicolumn{2}{|c|}{$\begin{array}{l}\text { Adherent to LAMA } \\
\text { (MPR } \geq 80 \% \text { ) }\end{array}$} & \multicolumn{2}{|c|}{$\begin{array}{l}\text { Nonadherent to LAMA } \\
\text { (MPR }<80 \%)\end{array}$} & \multicolumn{2}{|c|}{$\begin{array}{l}\text { Persistent with LAMA } \\
\text { (PDC } \geq \mathbf{8 0} \%)\end{array}$} & \multicolumn{2}{|c|}{$\begin{array}{l}\text { Not persistent with } \\
\text { LAMA (PDC }<\mathbf{8 0} \%)\end{array}$} \\
\hline & 12 months & 24 months & 12 months & 24 months & 12 months & 24 months & 12 months & 24 months \\
\hline All patients, $n$ & 817 & 727 & 2,205 & 2,295 & 579 & 449 & 2,443 & 2,573 \\
\hline Male & $413(50.6)$ & $381(52.4)$ & $I, 03 \mid(46.8)$ & $\mathrm{I}, 063(46.3)$ & $283(48.9)$ & $223(49.7)$ & $\mathrm{I}, 16 \mathrm{I}(47.5)$ & $\mathrm{I}, 22 \mathrm{I}(47.5)$ \\
\hline Age, mean (SD) & $56.8(4.8)$ & $56.8(4.8)$ & $55.2(5.6)$ & $55.4(5.6)$ & $57.2(4.6)$ & $57.2(4.4)$ & $55.4(5.4)$ & $55.4(5.4)$ \\
\hline \multicolumn{9}{|l|}{ Comorbidities } \\
\hline Charlson comorbidity & $1.4(2.0)$ & $\mathrm{I} .4(2.0)$ & $1.6(2.4)$ & $1.6(2.2)$ & I.4 (2.0) & $\mathrm{I} .4(2.0)$ & $1.6(2.2)$ & $1.6(2.2)$ \\
\hline \multicolumn{9}{|l|}{ index, mean (SD) } \\
\hline Asthma & $255(3 \mid .2)$ & $221(30.4)$ & $821(37.2)$ & $855(37.3)$ & $185(32.0)$ & I 40 (3|.2) & 891 (36.5) & $936(36.4)$ \\
\hline Myocardial infarction & $64(7.8)$ & $59(8.1)$ & $216(9.8)$ & $221(9.6)$ & $38(6.6)$ & $28(6.2)$ & $242(9.9)$ & $252(9.8)$ \\
\hline \multicolumn{9}{|l|}{ Exacerbations } \\
\hline None & $490(60.0)$ & $321(44.2)$ & $\mathrm{I}, 217(55.2)$ & $946(4 \mid .2)$ & $357(6 \mid .7)$ & $195(43.4)$ & $\mathrm{I}, 350(55.3)$ & $\mathrm{I}, 072(4 \mathrm{I} .7)$ \\
\hline 1 & $213(26.1)$ & $211(29.0)$ & $638(28.9)$ & $613(26.7)$ & $149(25.7)$ & $134(29.8)$ & $702(28.7)$ & $690(26.8)$ \\
\hline$\geq 2$ & $114(14.0)$ & $195(26.8)$ & $350(15.9)$ & $736(32.1)$ & $73(12.6)$ & $120(26.7)$ & $391(16.0)$ & $811(31.5)$ \\
\hline \multicolumn{9}{|l|}{ Moderate exacerbations } \\
\hline None & $573(70.1)$ & $417(57.4)$ & $\mathrm{I}, 465(66.4)$ & $\mathrm{I}, 208(52.6)$ & $4 \mid 3(7 \mid .3)$ & $256(57.0)$ & $1,625(66.5)$ & $1,369(53.2)$ \\
\hline 1 & $169(20.7)$ & $176(24.2)$ & $512(23.2)$ & $566(24.7)$ & $119(20.6)$ & II3 (25.2) & $562(23.0)$ & $629(24.4)$ \\
\hline$\geq 2$ & $75(9.2)$ & $134(18.4)$ & $228(10.3)$ & $521(22.7)$ & $47(8.1)$ & $80(17.8)$ & $256(10.5)$ & $575(22.3)$ \\
\hline \multicolumn{9}{|l|}{ Severe exacerbations } \\
\hline None & $695(85.1)$ & $546(75.1)$ & $\mathrm{I}, 846(83.7)$ & $\mathrm{I}, 764(76.9)$ & $497(85.8)$ & $334(74.4)$ & $2,044(83.7)$ & I,976 (76.8) \\
\hline 1 & $108(13.2)$ & $140(19.3)$ & $287(13.0)$ & $378(16.5)$ & $72(12.4)$ & $87(19.4)$ & $323(13.2)$ & $431(16.8)$ \\
\hline$\geq 2$ & $14(1.7)$ & $4 \mid(5.6)$ & $72(3.3)$ & $153(6.7)$ & $10(1.7)$ & $28(6.2)$ & $76(3.1)$ & $166(6.5)$ \\
\hline \multicolumn{9}{|l|}{ Oral corticosteroid use } \\
\hline None & $553(67.7)$ & $392(53.9)$ & $\mathrm{I}, 453(65.9)$ & $\mathrm{I}, 194(52.0)$ & $404(69.8)$ & $237(52.8)$ & I,602 (65.6) & I,349 (52.4) \\
\hline I & $140(17.1)$ & $159(21.9)$ & $450(20.4)$ & $512(22.3)$ & $91(15.7)$ & $102(22.7)$ & $499(20.4)$ & $569(22.1)$ \\
\hline$\geq 2$ & $124(15.2)$ & $176(24.2)$ & $302(13.7)$ & $589(25.7)$ & $84(14.5)$ & $110(24.5)$ & $342(14.0)$ & $655(25.5)$ \\
\hline \multicolumn{9}{|l|}{ Markers of disease severity } \\
\hline All-cause hospitalization & $132(16.2)$ & I 88 (25.9) & $413(18.7)$ & $660(28.8)$ & $80(13.8)$ & $107(23.8)$ & $465(19.0)$ & $74 I(28.8)$ \\
\hline Emphysema diagnosis & $109(13.3)$ & $137(18.8)$ & $225(10.2)$ & $319(13.9)$ & $86(14.9)$ & $95(21.2)$ & $248(10.2)$ & $361(14.0)$ \\
\hline $\begin{array}{l}\text { Lower respiratory tract } \\
\text { infections }\end{array}$ & $327(40.0)$ & $392(53.9)$ & $\mathrm{I}, 006(45.6)$ & $\mathrm{I}, 403(6 \mathrm{I} . \mathrm{I})$ & $231(39.9)$ & $249(55.5)$ & I, $102(45.1)$ & $\mathrm{I}, 546(60.1)$ \\
\hline Oxygen therapy & $95(11.6)$ & $110(15.1)$ & $244(11.1)$ & $319(13.9)$ & $74(12.8)$ & $73(16.3)$ & $265(10.8)$ & $356(13.8)$ \\
\hline SABD prescriptions & $486(59.5)$ & $495(68.1)$ & $\mathrm{I}, 150(52.2)$ & $\mathrm{I}, 437(62.6)$ & $349(60.3)$ & $321(71.5)$ & $\mathrm{I}, 287(52.7)$ & I,6II (62.6) \\
\hline Shortness of breath & $196(24.0)$ & $249(34.3)$ & $517(23.4)$ & $796(34.7)$ & $134(23.1)$ & $156(34.7)$ & $579(23.7)$ & $889(34.6)$ \\
\hline
\end{tabular}

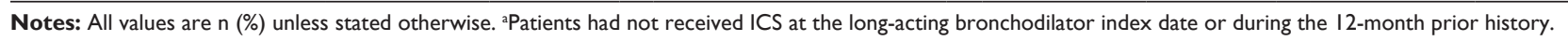
Abbreviations: ICS, inhaled corticosteroid; LAMA, long-acting muscarinic antagonist; MPR, medication possession ratio; PDC, proportion of days covered; SABD, shortacting bronchodilator; SD, standard deviation.

recognized that adherence to pharmacotherapy in COPD is generally suboptimal. ${ }^{21}$

The updated 2013 GOLD strategy recommends the use of SABD for bronchodilation, and consequently, an increase in the number of recorded SABD prescriptions dispensed may also indicate more symptoms and greater disease severity. ${ }^{7}$ These findings suggest that patients add or switch medications to improve symptom control. While the percentage of patients with events occurring in the 30 days before an addition or switch was small, poor control of symptoms is suggested by the proportion of patients who received a code for shortness of breath despite being dispensed an LAMA.

The proportion of patients who added to and switched from initial LAMA monotherapy in this study is comparable with observations from the Dutch PHARMO database (The PHARMO Institute, Utrecht, the Netherlands); after 12 months, the proportion of patients adding to LAMA monotherapy in this study was $10 \%$ compared with $15 \%$ in the PHARMO database, and the proportion of patients switching from LAMA monotherapy was $9 \%$ compared with $13 \%$, respectively. ${ }^{11}$ In this study, most patients who switched from LAMA monotherapy switched to ICS plus LABA after 12 months (80\%). The PHARMO database study reported a similar finding that $74 \%$ switched to ICS plus LABA after 12 months. ${ }^{11}$

Adherence to medication may be lower in COPD than in other chronic diseases. In a review of published electronic monitoring data, mean adherence to medication was $80 \%$ in 
cancer, $73 \%$ in diabetes, $71 \%$ in cardiovascular disease, $55 \%$ in asthma, and $51 \%$ in COPD. ${ }^{22}$ In this study, mean adherence rates were also low: mean adherence at 12 months was $65 \%$ for LAMA and $59 \%$ for LABA, and $59 \%$ for LAMA and $52 \%$ for LABA at 24 months.

The results are consistent with previous studies that documented low adherence rates with inhaled medications among COPD patients, regardless of medication class. The adherence rates of LABA monotherapy in this study (29\% at 12 months and $24 \%$ at 24 months) are comparable with observations from a Veterans Adminstration study in which the percentage of patients adherent to LABA at baseline was $31 \% .{ }^{23}$ The same Veterans Adminstration study showed that $20 \%$ were adherent to ICS and $26 \%$ were adherent to ipratropium bromide. In this study, adherence rates with LAMA monotherapy (40\% at 12 months and $33 \%$ at 24 months) were slightly better than those with the other medications, although they were still low.

In this study, $19 \%$ of patients were persistent with LAMA monotherapy over 12 months, and $15 \%$ were persistent over 24 months. These persistence rates are consistent with those reported in other studies; an analysis of drug-dispensing patterns in 1,028 patients initiating LAMA medication in the PHARMO database found that $25 \%$ and $14 \%$ of patients were persistent with LAMA therapy at 12 and 24 months, respectively. ${ }^{11}$ A retrospective analysis of prescription claims from a Canadian Drug Benefit Program reported that, of 4,888 patients who initiated LAMA, $27 \%$ and $24 \%$ of patients were persistent with therapy at 12 and 18 months, respectively. ${ }^{8}$ Thus, the results of this study are consistent with others, and suggest that persistence with LAMA monotherapy is low. In comparison, persistence with LABA therapy was even lower; $9 \%$ and $7 \%$ at 12 and 24 months, respectively.

Approximately one in four patients who initiated LAMA monotherapy had only one LAMA prescription at baseline. These patients had fewer OCS prescriptions dispensed, fewer severe exacerbations, and fewer SABD prescriptions dispensed before initiating LAMA monotherapy than patients who had more than one LAMA prescription. These results are consistent with an observational study from a French Health Insurance claims database in which $11 \%$ of patients who initiated LAMA (as monotherapy or in combination) had only one prescription for tiotropium. These patients were less likely to be classified as having long-term disease than patients with more prescriptions. ${ }^{10}$ These results suggest that patients who had only one LAMA prescription at baseline had less severe COPD than patients who had more than one LAMA prescription.

This study was not designed to examine adherence rates and medication evolution in patients with a history of ICScontaining therapy. The 3,326 patients who newly initiated LABD therapy with previous or concomitant ICS or ICS plus LABA use had more severe COPD compared with patients without ICS exposure in terms of number and severity of exacerbations, ICU visits, OCS use, SABD use, and oxygen therapy. Thus, the use of LABA or LAMA monotherapy is consistent with the GOLD strategy recommendation of first-line maintenance medication in patients with COPD, and long-term treatment with an ICS plus an LABD or a combination of LABDs is recommended in patients with a high risk of exacerbations. Patient experience and evolution of treatment is likely to be different among those with more severe disease, and thus any comparisons between patients receiving ICS-containing therapy with those receiving LABD monotherapy would be confounded by disease severity.

\section{Limitations}

The Truven Marketscan ${ }^{\circledR}$ Commercial Database is a sample of people in the US covered by private insurance plans affiliated with employment, so this study may not be representative of patients in the US who received health care through government organizations (eg, the Medicare population aged $\geq 65$ years) or who had no health insurance. Additionally, patients who did not seek care or treatment will not have been captured. The Truven Marketscan ${ }^{\circledR}$ Commercial Database captures only diagnosed diseases and dispensed medications, so only individuals with the necessary medical code or ICD-9 code with the required 12-month history and 24 months of follow-up were identified as patients in the cohort. Prescription claims only indicate pharmacotherapies dispensed by the pharmacy; patients' actual use of the medication is not captured in the database. Further, because there was an 18-month lag for data in the database to be complete, and allowing for 24 months of follow-up, only data before 2011 were used for this study. It is acknowledged that COPD diagnosis and care have improved since 2009.

The exclusion from the database of patients over age 65 years may influence the results, as it is likely to exclude patients with the most severe COPD. In younger patients, COPD is generally of mild-to-moderate severity; this is supported by the fact that in this study only about one-third of patients receiving LAMA monotherapy had a moderate exacerbation and $57 \%$ had no exacerbations in 12 months. The benefits of pharmacotherapy may not be obvious to 
patients with mild-to-moderate disease, and this may contribute to poor adherence with therapy.

The inability to study patients with COPD receiving LABD who died may impact on the interpretation of the study. Deaths were not included because the Truven Marketscan ${ }^{\circledR}$ Commercial Database only provides information on hospitalized deaths, and thus may not be representative of all patients who die during follow-up. Consequently, the study cohort may not be representative of patients with very severe COPD.

The study population was US-based, and reflects COPD management practices by US-based physicians. Consequently, it may not be possible to generalize the findings of the study to countries outside the US.

\section{Study strengths}

The Truven Marketscan ${ }^{\circledR}$ Commercial Database afforded a large sample size of patients in the US and represents an important addition to the literature on treatment evolution in patients with COPD, much of which has been reported from European studies. One of the problems with studying patients with COPD is identifying patients, and many patients with mild disease are underdiagnosed. ${ }^{24}$ In this study, patients with COPD were identified by the presence of an ICD-9 COPDrelated diagnostic code in their prior 12-month history and thus represent a group for which a COPD diagnosis can be verified. The study also reports prescriptions dispensed rather than only prescriptions written, and is therefore likely to be more representative of treatment actually received by patients.

\section{Conclusion}

A cohort of patients with COPD who were newly prescribed an LABD was identified from a US commercial database. The majority of patients were prescribed LAMA monotherapy. Over 24 months of follow-up, approximately one in four patients added to or switched from LAMA monotherapy. Adherence to newly initiated monotherapy was low in general, with many patients discontinuing therapy. Adherence to and persistence with LAMA and LABA monotherapy was low, and it is recognized that adherence to pharmacotherapy in COPD is generally poor. The patterns of prescription dispensing in additions to, switching from, and discontinuation of LAMA monotherapy, viewed alongside trends in SABD use, indicate that optimal disease control may not be achieved with LAMA monotherapy. Additional research to understand barriers to patient adherence behaviors, intentional and nonintentional adherence behaviors, and the reasons for adding or switching medication using patient-reported data are warranted to improve COPD outcomes.

\section{Acknowledgments}

This study (WEUSKOP5905) was funded by GlaxoSmithKline Research and Development (R\&D). Editorial support was provided by Jane Davies and Stephen Moore of Caudex Medical with funding from GlaxoSmithKline Plc.

\section{Disclosure}

All authors are employees of GlaxoSmithKline R\&D, and own stocks and shares in GlaxoSmithKline Plc. The authors have no further conflicts of interest in this work.

\section{References}

1. Brody H. Chronic obstructive pulmonary disease. Nature. 2012;489(7417):S1.

2. Rabe KF, Hurd S, Anzueto A, et al. Global strategy for the diagnosis, management, and prevention of chronic obstructive pulmonary disease: GOLD executive summary. Am J Respir Crit Care Med. 2007;176(6): 532-555.

3. Global Initiative for Chronic Obstructive Lung Disease (GOLD). Global Strategy for the Diagnosis, Management, and Preventation of Chronic Obstructive Pulmonary Disease (Revised 2011). Vancouver WA: Global Initiative for Chronic Obstructive Lung Disease; 2011. Available from: http://www.goldcopd.org/uploads/users/files/GOLD_Report_2011_ Feb21.pdf. Accessed December 3, 2012.

4. Rabe KF. Improving dyspnea in chronic obstructive pulmonary disease: optimal treatment strategies. Proc Am Thorac Soc. 2006;3(3): 270-275.

5. Dransfield MT, Bailey W, Crater G, Emmett A, O'Dell DM, Yawn B. Disease severity and symptoms among patients receiving monotherapy for COPD. Prim Care Respir J. 2011;20(1):46-53.

6. Global Initiative for Chronic Obstructive Lung Disease (GOLD). Global Strategy for the Diagnosis, Management, and Prevention of Chronic Obstructive Pulmonary Disease (2006). Vancouver, WA: Global Initiative for Chronic Obstructive Lung Disease; 2006. Available from: http://www. who.int/respiratory/copd/GOLD_WR_06.pdf. Accessed June 17, 2013.

7. Global Initiative for Chronic Obstructive Lung Disease (GOLD). Global Strategy for the Diagnosis, Management, and Prevention of Chronic Obstructive Pulmonary Disease (Updated 2013). Vancouver, WA: Global Initiative for Chronic Obstructive Lung Disease; 2013. Available from: http://www.goldcopd.org/uploads/users/files/GOLD_ Report_2013_Feb20.pdf. Accessed July 6, 2014.

8. Cramer JA, Bradley-Kennedy C, Scalera A. Treatment persistence and compliance with medications for chronic obstructive pulmonary disease. Can Respir J. 2007;14(1):25-29.

9. Breekveldt-Postma NS, Koerselman J, Erkens JA, Lammers JW, Herings RM. Enhanced persistence with tiotropium compared with other respiratory drugs in COPD. Respir Med. 2007;101(7): 1398-1405.

10. Laforest L, Licaj I, Devouassoux G, Hartwig S, Marvalin S, Van Ganse E. Factors associated with early adherence to tiotropium in chronic obstructive pulmonary disease. Chron Respir Dis. 2013;10(1): $11-18$.

11. Penning-van Beest F, van Herk-Sukel M, Gale R, Lammers JW, Herings R. Three-year dispensing patterns with long-acting inhaled drugs in COPD: a database analysis. Respir Med. 2011;105(2):259-265.

12. Hansen LG, Chang S. White Paper: Health Research Data for the Real World: The Marketscan ${ }^{\circledR}$ Databases. Ann Arbor, MI: Truven Health Analytics; 2012. 
13. Quan H, Sundararajan V, Halfon $P$, et al. Coding algorithms for defining comorbidities in ICD-9-CM and ICD-10 administrative data. Med Care. 2005;43(11):1130-1139.

14. Fairman K, Motheral B. Evaluating medication adherence: which measure is right for your program. J Manag Care Pharm. 2000;6(6): 499-504.

15. Cramer JA, Roy A, Burrell A, et al. Medication compliance and persistence: terminology and definitions. Value Health. 2008;11(1):44- 47.

16. Hurst JR, Vestbo J, Anzueto A, et al. Susceptibility to exacerbation in chronic obstructive pulmonary disease. $N$ Engl J Med. 2010;363(12): 1128-1138.

17. Col N, Fanale JE, Kronholm P. The role of medication noncompliance and adverse drug reactions in hospitalizations of the elderly. Arch Intern Med. 1990;150(4):841-845.

18. Cully JA, Graham DP, Stanley MA, et al. Quality of life in patients with chronic obstructive pulmonary disease and comorbid anxiety or depression. Psychosomatics. 2006;47(4):312-319.

19. Hughes CM. Medication nonadherence in the elderly: how big is the problem? Drugs Aging. 2004;21(12):793-811.
20. Incalzi RA, Gemma A, Marra C, Capparella O, Fuso L, Carbonin P. Verbal memory impairment in COPD: its mechanisms and clinical relevance. Chest. 1997;112(6):1506-1513.

21. Bourbeau J, Bartlett SJ. Patient adherence in COPD. Thorax. 2008; 63(9):831-838.

22. Claxton AJ, Cramer J, Pierce C. A systematic review of the associations between dose regimens and medication compliance. Clin Ther. 2001;23(8):1296-1310.

23. Huetsch JC, Uman JE, Udris EM, Au DH. Predictors of adherence to inhaled medications among veterans with COPD. J Gen Intern Med. 2012;27(11):1506-1512.

24. Lindberg A, Bjerg A, Ronmark E, Larsson LG, Lundback B. Prevalence and underdiagnosis of COPD by disease severity and the attributable fraction of smoking: report from the Obstructive Lung Disease in Northern Sweden Studies. Respir Med. 2006;100(2):264-272.
International Journal of COPD

\section{Publish your work in this journal}

The International Journal of COPD is an international, peer-reviewed journal of therapeutics and pharmacology focusing on concise rapid reporting of clinical studies and reviews in COPD. Special focus is given to the pathophysiological processes underlying the disease, intervention programs, patient focused education, and self management protocols.

\section{Dovepress}

This journal is indexed on PubMed Central, MedLine and CAS. The manuscript management system is completely online and includes a very quick and fair peer-review system, which is all easy to use. Visit http://www.dovepress.com/testimonials.php to read real quotes from published authors. 